\title{
Recria de bezerros em pastagem de aveia e azevém utilizando suplementação energética com níveis de promotor de crescimento ${ }^{1}$
}

\author{
Dairy calves raising in oat and ryegrass mixture utilizing energetic supplementation \\ with levels of growth promotor
}

\author{
Karen Döering Brustolin ${ }^{2}$ Fernando Luíz Ferreira de Quadros ${ }^{3}$ Julio Viégas ${ }^{3}$ \\ Alexandre Mossati Gabbi ${ }^{4}$ Silvane Barcellos Carlotto ${ }^{4}$ Adriano Ramos Cardoso ${ }^{4}$ \\ Priscila Guilhermano Fontoura ${ }^{5}$ Marcos André Piuco $^{5}$
}

\section{RESUMO}

O presente trabalho teve como objetivo avaliar a produção animal em pastagem de aveia (Avena strigosa Schreb) e azevém (Lolium multiflorum Lam.), recebendo ou não suplementação, com e sem promotor de crescimento. $O$ experimento foi conduzido no Setor de Bovinocultura de Leite do Departamento de Zootecnia da UFSM, no período de abril a setembro de 2003. Os animais utilizados foram bezerros machos desaleitados, da raça Holandês com idade média inicial de 3 meses e peso médio inicial de $88,7 \mathrm{~kg}$. Estes animais foram submetidos a pastejo contínuo com lotação fixa (carga média de $1.479 \mathrm{~kg}$ de Peso Vivo por hectare $\left.\left(P V \mathrm{ha}^{-1}\right)\right)$ em pastagem de aveia e azevém recebendo ou não suplementação, com e sem um promotor de crescimento natural à base de óleos essenciais extraídos de plantas. Os tratamentos foram: $S-0 \%=$ pastagem sem suplementação; $S-1 \%=$ pastagem $+1 \%$ do peso vivo $(P V)$ em matéria seca (MS) do suplemento ao dia; $S-1 \%$ PC250 = pastagem $+1 \%$ do PV em MS do suplemento ao dia (com $250 \mathrm{~g}$ de promotor de crescimento por tonelada de suplemento); $S-1 \%$ PC500 = pastagem $+1 \%$ do PV em MS do suplemento ao dia (com $500 \mathrm{~g}$ de promotor de crescimento por tonelada de suplemento). $O$ delineamento experimental utilizado foi o de um quadrado latino $4 \times 4$, com duas repetições. As medidas dos animais e seu ganho médio diário (GMD), a massa de forragem $(M F)$, altura da pastagem (ALT), taxa de acúmulo da pastagem (TAMS), taxa de desaparecimento de matéria seca (TDMS) e valor nutritivo da pastagem foram avaliadas. O GMD médio foi de $622 \mathrm{~g}_{\text {animal }}^{-1}$ dia $^{-1}$ para os animais suplementados e 294,5g animal $^{-1}$ dia $^{-1}$ para os não suplementados $(P<0,05)$. Os valores médios de massa de forragem $\left(943,9 \mathrm{~kg} \mathrm{ha}^{-1}, \mathrm{MS}\right)$, taxa de acúmulo $\left(142,7 \mathrm{~kg} \mathrm{ha}^{-1}\right.$ dia $\left.^{-1}, \mathrm{MS}\right)$ e taxa de desaparecimento de MS $(133,2 \mathrm{~kg}$ $h^{-1}$ dia $\left.^{-1}, M S\right)$ não foram influenciados pelos tratamentos $(P>0,05)$. As diferenças de MF total são conseqüência da taxa de desaparecimento, já que as taxas de acúmulo de matéria seca foram semelhantes. O promotor de crescimento não afetou $o$ desempenho e o desenvolvimento dos animais.

Palavras-chave: bezerros leiteiros, pastagem de estação fria, concentrado, promotor de crescimento.

\section{ABSTRACT}

The objective was to evaluate the animal production on oat (Avena strigosa Schreb) and ryegrass (Lolium multiflorum Lam.) mixed pasture, receiving or not receiving supplementation, with and without growth promoter. The experiment was conducted in Dairy Sector at Departamento de Zootecnia, Universidade Federal de Santa Maria, RS, Brazil, during the period of April to September, 2003. The utilised animals were weaned male dairy calves, Holstein breed, with initial average age of three months and initial average live weight (LW) of $88.7 \mathrm{~kg}$. The animals were submitted to continuous grazing with

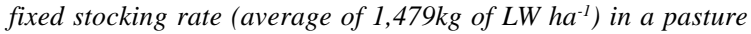
of oat and ryegrass receiving or not supplementation, with and without a growth promoter based on essential oils from plants. Treatments were: $S-0 \%=$ cool season pasture without supplementation; $S-1 \%=$ pasture $+1 \% L W$ as DM of supplement; $S-1 \%$ PC250=pasture $+1 \%$ of LW as DM of supplement (with $250 \mathrm{~g}$ growth promoter for ton of supplement); $S-1 \%$

${ }^{1}$ Parte da Dissertação de Mestrado da primeira autora, apresentada à Universidade Federal de Santa Maria (UFSM), parcialmente financiada pelo Conselho Nacional de Desenvolvimento Científico e Tecnológico (CNPq).

${ }^{2}$ Engenheiro Agrônomo, Mestre em Zootecnia, UFSM, Santa Maria, RS. Autor para correspondência. Borges de Medeiros, 303, 99600000, Nonoai, RS. E-mail: karen.db@ibest.com.br

${ }^{3}$ Engenheiro Agrônomo, Professor do Departamento de Zootecnia, UFSM

${ }^{4}$ Zootecnista, Estudante de Mestrado, UFSM.

${ }^{5}$ Estudante de Zootecnia, UFSM. 
PC500=pasture $+1 \%$ LW as DM of supplement (with 500g growth promoter for ton of supplement). The experiment design utilised was a Latin Square $4 x 4$, with two repetitions. Body measures and daily weight gain (DWG) of animals; forage height and mass, $D M$ accumulation rate of the pasture, DM disappearance rate of the pasture and forage quality were evaluated. The average $D W G$ was $622 \mathrm{~g}_{\text {animal }}{ }^{-1}$ day ${ }^{-1}$ to the supplemented animals and $294.5 \mathrm{~g}$ animal $^{-1}$ day $^{-1}$ to the non-supplemented animals $(P<0.05)$. Average values for forage mass (943.9 $\mathrm{kg} \mathrm{ha}^{-1}$ of DM ), daily accumulation rate (142.7 $\mathrm{kg} \mathrm{ha}^{-1}$ day $^{-1}$ of DM) and DM disappearance rate (133.2 $\mathrm{kg} \mathrm{ha}^{-1}$ day $^{-1}$ of DM) were not influenced by treatments $(P>0.05)$. The growth promoter did not affect animal performance and development.

Key words: dairy calves, cool season pasture, concentrate, growth promoter.

\section{INTRODUÇÃO}

A produção animal em pastagens é dependente da relação entre o comportamento animal e a produção e a qualidade da forragem. A utilização de pastagens de gramíneas anuais é uma alternativa para suprir o déficit alimentar na estação fria que tem sido útil na recria de bezerros machos de origem leiteira. A mistura de aveia e azevém tem demonstrado um elevado potencial forrageiro com bons rendimentos de ganho de peso.

A suplementação com concentrados pode ser usada para otimizar a utilização de pastagens hibernais através de incrementos no desempenho individual dos animais e na produção animal por unidade de área (SANTOS et al., 2002). Para o uso de suplementação na alimentação animal, é preciso conhecer a necessidade nutricional do animal, conforme sua categoria e idade, e quanto do suplemento deve ser fornecido para atingir os objetivos. Com o uso de suplemento, normalmente há um aumento no consumo total de energia e consequientemente, um melhor desempenho do animal. MOLETTA \& PEROTTO (1997) concluíram que a utilização de suplemento concentrado é fundamental para que terneiros, desmamados precocemente, apresentem desempenho semelhante aos criados junto à vaca, e que a utilização exclusiva de pastagens não proporciona condições para um bom desenvolvimento dos animais até os sete meses de idade.

A adição de promotores de crescimento como antibióticos, ionóforos ou probióticos na alimentação animal, podem aumentar o crescimento e reduzir a quantidade de alimento usado para um dado ganho de peso, diminuindo o tempo necessário para que os animais fiquem aptos para a comercialização e aumentando, conseqüentemente, o lucro para o produtor (MAYNARD \& LOOSLI, 1974). Contudo, os resultados experimentais usando probióticos ainda são muito variáveis, necessitando-se mesmo de uma melhor categorização para esses aditivos. Por exemplo, para bezerros da raça holandesa no período de aleitamento, a adição de um probiótico composto por Saccharomyces cerevisiae, Enterococcus faecium e Lactobacillus acidophilus, proporcionam melhorias no ganho de peso vivo e na conversão alimentar nestes animais (MEYER et al., 2001). Já novilhos de 300kg de peso vivo, tratados com cana-de-açúcar e suplementados como fonte de nitrogênio, Saccharomyces cerevisiae, não apresentaram influências em relação a sua produção microbiana ruminal (PEREIRA et al., 2003).

Assim, o objetivo deste trabalho foi avaliar o desempenho de bezerros machos, da raça Holandês, em pastagem de aveia e azevém, utilizando suplementação energética com diferentes níveis de um promotor natural de crescimento à base de óleos essenciais.

\section{MATERIAL E MÉTODOS}

Este trabalho foi realizado no Setor de Bovinocultura de Leite do Departamento de Zootecnia da Universidade Federal de Santa Maria - RS, no período de abril a setembro de 2003 . O clima da região é o Cfa, subtropical úmido, segundo a classificação de Köppen (MORENO, 1961). A área experimental está situada a $29^{\circ} 43^{\prime}$ de latitude Sul e $53^{\circ} 42^{\prime}$ de longitude Oeste, numa altitude de $95 \mathrm{~m}$. O solo é classificado como ARGISSOLO VERMELHO Distrófico Arênico (EMBRAPA, 1999).

A área destinada ao experimento foi de 0,6 hectare de Aveia e Azevém, subdividida por cerca elétrica em oito piquetes de $750 \mathrm{~m}^{2}$ cada um. A cada dois piquetes, havia um tanque com água disponível. A implantação da pastagem foi no dia 02 de abril de 2003. A semeadura foi a lanço, com densidade de $80 \mathrm{~kg}$ $\mathrm{ha}^{-1}$ de sementes de aveia e $40 \mathrm{~kg} \mathrm{ha}^{-1}$ de sementes de azevém. Foram aplicados $150 \mathrm{~kg}$ de adubo na fórmula 5-20-20 e 123,2kg de N, na forma de uréia. A adubação nitrogenada foi parcelada em quatro aplicações, nos dias 05/04, 23/06, 12/07 e 25/08. Os animais utilizados foram oito bezerros machos desaleitados, da raça Holandês preto e branco, com peso médio inicial de $88,7 \mathrm{~kg}$, oriundos do Setor de Bovinocultura de Leite da UFSM. O experimento ocorreu do terceiro ao sexto mês de vida dos animais.

$\mathrm{O}$ experimento seguiu um delineamento experimental em quadrado latino $4 \times 4$, com duas repetições, sendo, quatro animais em cada um dos quatro períodos. Os períodos foram de 21 dias. Desses, 14 dias foram para fase de adaptação e sete dias para 
fase de coleta. $\mathrm{O}$ objetivo principal de utilizar o quadrado latino foi aumentar o número de graus de liberdade para o erro experimental, usando um menor número de animais como repetições. Os potreiros estiveram alocados sempre aos mesmos tratamentos e os animais eram trocados segundo a seqüência do quadrado latino, sendo as linhas constituídas pelos períodos e as colunas pelos animais. Para avaliação de pastagem, considerou-se um delineamento completamente casualizado.

Os bezerros foram submetidos a pastejo contínuo, recebendo ou não suplementação. A oferta de forragem variou devido à limitação do tamanho da unidade experimental $\left(750 \mathrm{~m}^{2}\right)$, variando de 1,1 a 3,14kg de MS/100kg PV/dia. Esta suplementação foi baseada em um concentrado comercial, com e sem a adição de um promotor de crescimento natural, à base de óleos essenciais extraídos de plantas (de nome comercial Fresta F Concä). Os animais foram submetidos aos seguintes tratamentos: $\mathrm{S}-0 \%=$ pastagem sem suplementação; $\mathrm{S}-1 \%=$ pastagem $+1 \%$ do PV em MS do suplemento; S-1\% PC250= pastagem $+1 \%$ do PV em MS do suplemento (com $250 \mathrm{~g}$ de promotor de crescimento por tonelada de suplemento) e S-1\% PC500 = pastagem $+1 \%$ do PV em MS do suplemento (com $500 \mathrm{~g}$ de promotor de crescimento por tonelada de suplemento).

O suplemento foi calculado conforme os requerimentos nutricionais contidos nas tabelas do Nutrient Requirements of Dairy Cattle (NRC, 2001), sendo que a ração foi formulada utilizando grão de sorgo moído, aveia, triguilho, cevada, farelo de trigo, linhaça, fosfato bicálcico, farinha de ossos, supermix e sal. Esta ração apresentou a seguinte proporção de nutrientes: $\mathrm{PB}=19,27 \%$; $\mathrm{MS}=86,77 \% ; \mathrm{MO}=89,4 \%$; $\mathrm{FDN}=22,9 \% ; \mathrm{NDT}=70,0 \% ; \mathrm{Ca}=2,0 \% ; \mathrm{P}=0,6 \%$.

O Fresta $\mathrm{F} \mathrm{Conc}^{\mathrm{TM}}$ apresenta na sua composição óleos essenciais de Hypericum perforatum (Erva de São João), Allium sativum (Alho), Rosmarinus officinalis (Alecrim) $e$ Thymus vulgaris (Tomilho) como sendo os principais componentes. Outros componentes do produto, utilizados em menores quantidades, são óleos essenciais de Origanum majorana (Orégano), Mentha piperita (Menta), Juniperus communis (Juniper) e Allium cepa (Cebola).

O consumo do suplemento foi mensurado através de pesagens, no momento da oferta, feita uma vez ao dia e posteriormente descontadas as sobras, quando houve, na alimentação do dia seguinte. $O$ suplemento foi fornecido diária e individualmente, às 10:30 horas. O consumo total foi obtido multiplicandose o consumo diário pelo número de dias das quatro fases experimentais (24/06 a $14 / 07 ; 15 / 07$ a $04 / 08$; 05/08 a 25/08 e 26/08/ a 16/09). O aumento do consumo foi crescente até ao final do experimento. A quantidade de suplemento foi ajustada no início de cada período, e não foi modificada até o final do mesmo, portanto, os animais começavam com $1 \%$ de suplemento em relação ao PV e, em função do crescimento e desenvolvimento do animal, chegavam ao final do período recebendo uma quantidade inferior a $1 \%$ do seu PV.

As avaliações dos animais foram realizadas no $14^{\circ}$ e $21^{\circ}$ dia de cada período, sendo que estes dados do $21^{\circ}$ dia foram utilizados como peso final do período e também peso inicial para o próximo período. As avaliações da pastagem foram a cada 21 dias, conforme mudança de período experimental, considerando início e final de cada período. Os animais foram pesados para estimar o ganho de peso médio diário (variável peso de balança $(\mathrm{Pb})$ ), e medidos no tórax com trena específica para estimar o peso corporal da raça (variável peso estimado pela trena $(\mathrm{Pt})$ ), e tomadas medidas da altura de cernelha, perímetro torácico e perímetro abdominal. Para estas avaliações, os animais foram submetidos a um jejum prévio de sólidos e líquidos de aproximadamente 14 horas. A carga animal variou de $1.278 ; 1.373 ; 1.512$ a $1.680 \mathrm{~kg}$ PV ha ${ }^{-1}$, seguindo a seqüência dos quatro períodos.

As estimativas de massa de forragem disponível na pastagem foram realizadas através da técnica Botanal proposta por TOTHILL et al. (1992). Em cada piquete, foram feitas 10 estimativas visuais da massa de forragem e quatro cortes rente ao solo em um disco de $32,5 \mathrm{~cm}$ de diâmetro, com área total de $0,0829 \mathrm{~m}^{2}$, para estimativa da massa de forragem e para a calibração do Botanal. As amostras cortadas foram pesadas e levadas à estufa de ar forçado a $55^{\circ} \mathrm{C}$ por aproximadamente 72 horas para determinação do percentual de MS da pastagem.

A estimativa da altura média da pastagem foi através do uso do disco medidor de forragem. Foram feitas 30 medidas com este disco em cada piquete. A taxa de acúmulo de matéria seca foi determinada com a utilização de gaiolas de exclusão de pastejo, conforme a descrição feita por GARDNER (1986). A taxa de desaparecimento da pastagem foi estimada através da equação recomendada por MORAES (1991), que inclui consumo aparente mais perdas (senescência, pisoteio, ...). O teor de nitrogênio da forragem foi determinado através do método micro Kjeldahl (AOAC, 1984). Para a análise da FDN, foi utilizada a metodologia descrita por GOERING \& VAN SOEST (1970).

Ciência Rural, v.35, n.2, mar-abr, 2005. 
Após a coleta dos dados, os resultados dos animais foram submetidos à análise de variância e teste de Tukey ao nível de 5\% de significância, quando houve diferenças significativas, utilizando-se o pacote estatístico SAS (1996). Para os dados da pastagem, as análises foram realizadas utilizando a rotina de testes de aleatorização do programa estatístico MULTIV (PILLAR, 1997).

\section{RESULTADOS E DISCUSSÃO}

Na tabela 1, são apresentados os valores médios encontrados em cada tratamento para peso de balança $(\mathrm{Pb}, \mathrm{kg})$, peso de fita $(\mathrm{Pf}, \mathrm{kg})$, ganho médio diário (GMD, g), altura (Alt, $\mathrm{m})$, perímetro torácico (PT, m) e perímetro abdominal (PA, m) dos animais.

O GMD diferiu entre o tratamento sem suplementação (S-0\%) e os demais tratamentos. Os tratamentos com suplementação não diferiram entre si. Estes dados são semelhantes aos de NÖRNBERG et al. (1993) que, trabalhando com diferentes níveis de Olaquindox, como estimulante do crescimento para bezerros leiteiros desaleitados precocemente, observaram um GMD de $617 \mathrm{~g}$ animal ${ }^{-1} \mathrm{dia}^{-1}$, e não encontraram diferenças significativas entre os tratamentos com e sem Olaquindox. Os valores de GMD do tratamento S-0\% foram inferiores aos dados de COELHO FILHO et al. (1996), que avaliando sistemas alimentares para bezerros de corte, desmamados aos três meses de idade, encontraram um ganho médio diário de $637 \mathrm{~g}$ animal ${ }^{1} \mathrm{dia}^{-1}$ em campo nativo com aveia e azevém, e $811 \mathrm{~g}$ animal ${ }^{-1} \mathrm{dia}^{-1} \mathrm{em}$ pastagem de pensacola com aveia e azevém.
Foi ajustada uma equação de regressão $(\mathrm{y}=12,29+0,83 \mathrm{X})$ entre as variáveis peso de balança $(\mathrm{Pb})$ e peso estimado pela trena $(\mathrm{Pt})$, obtendo-se uma diferença altamente significativa, um alto coeficiente de determinação $\left(\mathrm{R}^{2}=0,87\right)$ e um baixo erro padrão $(5,9 \mathrm{~kg})$. Estes resultados indicam a confiabilidade do uso da trena em propriedades que não dispõem de balança para controlar o desenvolvimento de bezerros leiteiros.

O consumo total do suplemento apresentou diferença significativa apenas entre os períodos. Esta diferença ocorreu apenas do primeiro (24/06-14/07) para os demais períodos, variando de 18 a $23 \mathrm{~kg}$ de MS, o que representou em média um percentual de $0,94 \%$ do PV dos animais.

Na tabela 2, são apresentadas as médias de massa de forragem (MF), taxa de acúmulo de matéria seca (TAMS), taxa de desaparecimento de matéria seca, teor de proteína bruta e fibra em detergente neutro da pastagem nos tratamentos e nos quatro períodos de avaliações.

A MF total foi influenciada pelos tratamentos e não pelos períodos. A MF diferiu do tratamento S-0\% para o tratamento S-1\%, os tratamentos com promotor de crescimento foram semelhantes $(\mathrm{P}>0,05)$ aos anteriores.

Para a variável taxa de acúmulo de matéria seca, foram encontradas diferenças significativas apenas entre os períodos, sendo que o valor mais alto foi no primeiro período de 24/06-14/07 (254,49 $\mathrm{kg} \mathrm{ha}^{-1}$ $\mathrm{dia}^{-1}$ de MS) e o mais baixo em 15/07-04/08 (63,49kg $\mathrm{ha}^{-1} \mathrm{dia}^{-1}$ de MS). Estes dados são superiores ao encontrados em trabalhos semelhantes. GONÇALVES et al. (2002), utilizando $150 \mathrm{~kg} \mathrm{ha}^{-1}$ de $\mathrm{N}$, obtiveram

Tabela 1 - Peso de balança (Pb, kg), peso estimado pela trena (Pt, kg), ganho médio diário (GMD, g), altura (Alt, m), perímetro torácico (PT, $\mathrm{m})$, perímetro abdominal (PA, m) de bezerros da raça Holandes, suplementados ou não em pastagem de aveia/azevém submetida a pastejo contínuo.

\begin{tabular}{|c|c|c|c|c|c|c|}
\hline Trats & $\mathrm{Pb}(\mathrm{kg})$ & Pt (kg) & GMD & Alt & PT & PA \\
\hline S-0\% & 113,5 & 121,5 & $294,5^{\mathrm{b}}$ & 1,00 & 1,18 & 1,23 \\
\hline S-1\% & 112,9 & 124,2 & $588,3^{\mathrm{a}}$ & 1,00 & 1,18 & 1,23 \\
\hline $\mathrm{S}-1 \% \mathrm{PC} 250$ & 114,5 & 119,4 & $624,8^{\mathrm{a}}$ & 1,00 & 1,20 & 1,23 \\
\hline S-1\%PC500 & 119,9 & 131,4 & $654,7^{\mathrm{a}}$ & 1,02 & 1,21 & 1,27 \\
\hline Média & 115,2 & 124,1 & 540,5 & 1,00 & 1,19 & 1,24 \\
\hline $\mathrm{F}$ & 0,5 & 1,1 & 10,3 & 1,03 & 0,8 & 0,99 \\
\hline $\mathrm{P}<$ & 0,7 & 0,4 & 0,0001 & 0,4 & 0,5 & 0,41 \\
\hline $\mathrm{CV}(\%)$ & 10,8 & 11,4 & 27,1 & 2,4 & 2,1 & 5,03 \\
\hline
\end{tabular}

S-0\% = pastagem sem suplementação; S-1\% = pastagem + 1\% do peso vivo (PV) em matéria seca (MS) do suplemento ao dia; S-1\% PC250 $=$ pastagem $+1 \%$ do PV em MS do suplemento ao dia $($ com $250 \mathrm{~g}$ de promotor de crescimento por tonelada de suplemento $) ; \mathrm{S}-1 \%$ PC500 = pastagem $+1 \%$ do PV em MS do suplemento ao dia $(\operatorname{com} 500 \mathrm{~g}$ de promotor de crescimento por tonelada de suplemento). $\mathrm{F}=$ valor de $\mathrm{F} ; \mathrm{P}=$ Probabilidade; $\mathrm{CV}=$ Coeficiente de variação.

a,b,c - Na coluna, médias seguidas de letras diferentes são significativamente diferentes entre si pelo teste de Tukey em nível de 5\% de significância. 
Tabela 2- Médias de massa de forragem (kg.ha ${ }^{-1} \mathrm{MS}$ ), taxa de acúmulo de matéria seca ( $\mathrm{kg} \mathrm{ha}^{-1}$ dia ${ }^{-1}$ de MS), taxa de desaparecimento de matéria seca ( $\mathrm{kg} \mathrm{ha}^{-1} \mathrm{dia}^{-1}$ de MS), teor de proteína bruta (\%) e de Fibra em Detergente Neutro (\%) da pastagem dos tratamentos, nos diferentes períodos de avaliações.

\begin{tabular}{|c|c|c|c|c|c|c|}
\hline \multirow{2}{*}{ Tratamentos } & \multirow{2}{*}{$\begin{array}{l}\text { Massa de forragem } \\
\qquad\left(\mathrm{kg} \mathrm{ha}^{-1}, \mathrm{MS}\right)\end{array}$} & \multirow{2}{*}{$\begin{array}{l}\text { Taxa de acúmulo } \\
\left(\mathrm{kg} \mathrm{ha}^{-1} \mathrm{dia}^{-1}, \mathrm{MS}\right)\end{array}$} & \multicolumn{2}{|c|}{ Taxa de desaparecimento } & \multirow{2}{*}{ PB (\%) } & \multirow{2}{*}{ FDN (\%) } \\
\hline & & & $\left(\mathrm{kg} \mathrm{ha}^{-1} \mathrm{dia}^{-1}, \mathrm{MS}\right)$ & $\% \mathrm{PV}$ & & \\
\hline $\mathrm{S}-0 \%$ & $855,7^{\mathrm{b}}$ & 147,8 & 139,3 & $7,7^{\mathrm{b}}$ & 24,2 & $51,2^{\mathrm{ab}}$ \\
\hline S- $1 \%$ & $1072,1^{\mathrm{a}}$ & 182,3 & 165,3 & $16,5^{\mathrm{a}}$ & 23,6 & $50,3^{\mathrm{b}}$ \\
\hline $\mathrm{S}-1 \% \mathrm{PC} 250$ & $917,7^{\mathrm{ab}}$ & 116,9 & 115,6 & $11,8^{\mathrm{a}}$ & 23,8 & $51,2^{\text {ab }}$ \\
\hline S-1\%PC500 & $930,1^{\mathrm{ab}}$ & 123,8 & 112,6 & $13,5^{\mathrm{a}}$ & 22,0 & $53,7^{\mathrm{a}}$ \\
\hline \multicolumn{7}{|l|}{ Períodos } \\
\hline $24 / 06-14 / 07$ & 979,9 & $254,5^{\mathrm{a}}$ & $193,4^{\mathrm{a}}$ & 9,9 & $24,2^{\mathrm{ab}}$ & 51,4 \\
\hline $15 / 07-04 / 08$ & 962,2 & $63,5^{\mathrm{c}}$ & $91,1^{\mathrm{b}}$ & 8,5 & $25,9^{\mathrm{a}}$ & 50,5 \\
\hline $05 / 08-25-08$ & 856,6 & $86,4^{\text {bc }}$ & $129,4^{\mathrm{ab}}$ & 13,9 & $22,3^{\mathrm{bc}}$ & 51,6 \\
\hline $26 / 08-16 / 09$ & 976,9 & $166,3^{\mathrm{ab}}$ & $118,8^{\mathrm{b}}$ & 15,5 & $21,3^{\mathrm{c}}$ & 52,9 \\
\hline
\end{tabular}

$\mathrm{S}-0 \%=$ pastagem sem suplementação; $\mathrm{S}-1 \%$ = pastagem $+1 \%$ do peso vivo (PV) em matéria seca (MS) do suplemento ao dia; $\mathrm{S}-1 \%$ PC250 $=$ pastagem $+1 \%$ do PV em MS do suplemento ao dia (com 250g de promotor de crescimento por tonelada de suplemento); $\mathrm{S}-1 \%$ PC500 = pastagem $+1 \%$ do PV em MS do suplemento ao dia (com 500g de promotor de crescimento por tonelada de suplemento).

Letras minúsculas na coluna diferem estatisticamente entre si pelo teste de aleatorização $(\mathrm{P}<0,05)$.

em agosto uma TAMS média de 41,86kg ha $\mathrm{hia}^{-1} \mathrm{de}$ MS. MARTINS et al. (2003), utilizando $100 \mathrm{~kg} \mathrm{ha}^{-1} \mathrm{de}$ $\mathrm{N}$, encontraram valores médios de $46,9 \mathrm{~kg} \mathrm{ha}^{-1} \mathrm{dia}^{-1} \mathrm{de}$ MS (05/07-09/08) e 48,45kg ha-1 $\mathrm{dia}^{-1}$ de MS (10/0813/09).

O somatório das MF das espécies mais as taxas de acúmulo, mantiveram a disponibilidade de forragem em valores que poderiam ser limitantes ao consumo. Segundo MOTT (1984), para que não exista limitação no consumo, a massa de forragem deve permanecer, no mínimo entre 1200 a $1600 \mathrm{~kg} \mathrm{ha}^{-1} \mathrm{de}$ MS, e a oferta de forragem ser sempre superior ao nível de 4 a 6\% do PV. Entretanto, SILVA et al. (2003), utilizando níveis de massa de forragem verde de 700 e $1200 \mathrm{~kg} \mathrm{ha}^{-1}$ de MS, demonstraram que, mesmo obtendo valores baixos de massa de forragem no mês de agosto (498,5 $\mathrm{kg} \mathrm{ha}^{-1}$ de MS), as variáveis de ganho médio diário, carga animal e ganho de peso vivo por hectare não foram afetadas. Isso indica que, para estas espécies forrageiras, o nível limitante pode ser mais baixo que as indicações iniciais.

Com relação à taxa de desaparecimento de matéria seca, também foram encontradas diferenças somente entre os períodos. Nos valores expressos em \% PV, foram encontrados valores extremos de 8,54 e 15,53. Esses dados foram superiores aos encontrados por ROSO \& RESTLE (2000) os quais trabalhando com aveia e azevém encontraram valores variaram de 4,043 a 4,559. As taxas de desaparecimento de MS foram mais altas devido ao experimento ter sido com lotação fixa, sem uso de animais reguladores. Como a lotação fixa não permite utilizar toda a taxa de acúmulo da pastagem, resulta em um maior volume de perdas por senescência e forragem desperdiçada por pisoteio. Entre os tratamentos, as maiores taxas de desaparecimento observadas, naqueles suplementados, podem ser atribuídas a uma maior taxa de senescência da forragem rejeitada pelo efeito substitutivo de consumo do suplemento.

Os teores de PB não foram afetados pelos tratamentos, mas foram influenciados significativamente pelos períodos. Os teores de PB foram mais elevados nos dois primeiros períodos (24/06-04/08) tendo decrescido a partir daí, o que é justificado pelo estádio de desenvolvimento das plantas. Estes dados são semelhantes aos encontrados por PILAU (2003) que, avaliando esta mistura durante 94 dias de pastejo, observou a manutenção do teor de PB acima de $18 \%$. Segundo SANTOS (2003), o teor de $15 \%$ de PB da forragem não foi limitante para ganhos de pesos elevados e, este teor protéico mais a utilização de suplementação com grão de milho, promoveu taxas de ganhos de pesos dos animais superiores a $1,0 \mathrm{~g}$ animal ${ }^{-1} \mathrm{dia}^{-1}$.

Para os teores de FDN, o efeito dos tratamentos foi significativo, sendo que o maior valor foi $53,75 \%$ no tratamento S-1\%PC500, e o menor $50,325 \%$ no tratamento $\mathrm{S}-1 \%(\mathrm{P}<0,05)$. Estes valores são intermediários aos valores encontrados em trabalhos com estas espécies, mas em cultivo solteiro. Em trabalho realizado com azevém, FREITAS et al. (2003) encontraram valor médio de 60,5\% de FDN da forragem. GALBEIRO et al. (2003), em trabalho

Ciência Rural, v.35, n.2, mar-abr, 2005. 
com várias linhagens de aveia, encontraram valor médio de $46 \%$ de FDN para aveia preta comum.

\section{CONCLUSÕES}

A utilização de suplementação energética em pastagens de estação fria aumenta o ganho de peso vivo de bezerros leiteiros dos três aos seis meses de idade. A adição do promotor de crescimento à base de óleos essenciais, nos níveis avaliados, não afeta o ganho médio diário nem o desenvolvimento de bezerros desaleitados da raça Holandês.

\section{REFERÊNCIAS BIBLIOGRÁFICAS}

ASSOCIATION OF OFFICIALANALYTICALCHEMISTS-AOAC. Official methods of analysis. 14.ed. Washington, 1984. 1141p.

COELHO FILHO, R.C. et al. Avaliação de sistemas alimentares para terneiros desmamados aos três meses de idade. Ciência Rural, v.26, n.1, p.129-134, 1996.

EMBRAPA. Centro Nacional de Pesquisa de Solos. Sistema brasileiro de classificação de solos. Brasília : EMBRAPA. Brasília, 1999. 412p.

FREITAS, T.M.S. et al. Produção de cordeiros em pastagem de azevém (Lolium multiflorum Lam.) submetida a doses de nitrogênio. 1. Características da pastagem. In: REUNIÃO ANUAL DA SOCIEDADE BRASILEIRA DE ZOOTECNIA, 40., 2003, Santa Maria. Anais... Santa Maria : Sociedade Brasileira de Zootecnia, 2003. CD-ROM

GALBEIRO, S. et al. Produção de forragem e características qualitativas de cultivares e linhagens de aveia na região noroeste do Paraná. In: REUNIÃO ANUAL DA SOCIEDADE BRASILEIRA DE ZOOTECNIA, 40., 2003, Santa Maria. Anais... Santa Maria : Sociedade Brasileira de Zootecnia, 2003. CD-ROM.

GARDNER, A.L. Técnicas de pesquisa em pastagens e aplicabilidade de resultados em sistemas de produção. Brasília: IICA/EMBRAPA-CNPGL, 1986. 197p

GOERING, H.K.; VAN SOEST, P.J. Forage fiber analysis. (apparates, reagents, procedures and some applications). Madison : USDAAgricultural Research Service, 1970. (Handbook number 379).

GONÇALVES, E.N. et al. Dinâmica de uma pastagem de aveia (Avena strigosa Schreb) mais azevém (Lolium multiflorum Lam.) com ou sem o uso de suplementação para bezerras de corte. In: REUNIÃO ANUAL DA SOCIEDADE BRASILEIRA DE ZOOTECNIA, 39., 2002, Recife. Anais... Recife : Sociedade Brasileira de Zootecnia, 2002. CDROOM.

MARTINS, C.E.N. et al. Dinâmica de uma pastagem de aveia (Avena strigosa Schreb) mais azevém (Lolium multiflorum Lam.) submetida a diferentes níveis de biomassa de lâmina foliar verde. In: REUNIÃO ANUAL DA SOCIEDADE BRASILEIRA DE ZOOTECNIA, 40., 2003, Santa Maria. Anais... Santa Maria : Sociedade Brasileira de Zootecnia, 2003. CD-ROM
MAYNARD, L.A.; LOOSLI, J.K. Nutrição animal. 2.ed. Rio de Janeiro : Freitas Bastos, 1974. Cap. 9, p.283-300

MEYER, P.M. et al. Adição de probiótico ao leite integral ou sucedâneo e desempenho de bezerros da raça holandesa. Scientia Agricola, Piracicaba, v.58, n.2, 2001. Acesso em 26/11/2004. On line. Disponível no site: http://www.scielo.br/scielo.php

MOLETTA, J.L.; PEROTTO, D. Efeito do manejo alimentar no pré e/ou pós-desmame, sobre o desempenho e características de carcaça de novilhos. In: REUNIÃO ANUAL DA SOCIEDADE BRASILEIRA DE ZOOTECNIA, 34., 1997, Juiz de Fora. Anais... Juiz de Fora : SBZ, 1997. p.72.

MORAES, A. de. Produtividade animal e dinâmica de uma pastagem de pangola (Digitaria decumbens), azevém (Lolium multiflorum) e trevo branco (Trifolium repens), submetida a diferentes pressões de pastejo. 1991. 200f. Tese (Doutorado em Zootecnia) - Universidade Federal do Rio Grande do Sul.

MOREnO, J.A. Clima do Rio Grande do Sul. Porto Alegre: Secretaria da Agricultura, 1961. 41p.

MOTT, G.O. Relationship of available forage and animal performance in tropical grazing systems. In: FORAGE AND GRASSLAND CONFERENCE, 1984, Huston, Texas. Forage systems: leading U.S. agriculture into future. Lexington: American Forage and Grassland Council, 1984. p.373-377.

NATIONAL RESEARCH COUNCIL - N.R.C. Nutrient requeriments of dairy cattle. Washington, DC. : National Academy of Science, 2001. 381p.

NÖRNBERG, J.L. et al. Valor de Olaquindox como estimulante do crescimento de terneiros leiteiros desaleitados precocemente. Revista Brasileira de Zootecnia, v.22, n.2, p.299-307, 1993.

PEREIRA, P.M. et al. Dinâmica dos nutrientes no trato gastro intestinal de novilhos holandeses alimentados com dietas à base de cana-de-açúcar. Revista Brasileira de Zootecnia, v.32, n.6, 2003. Acesso em 26/11/2004. On line. Disponível no site: http:/ /www.scielo.br/scielo.php

PILAU, A. Alternativas de utilização de suplementação energética para recria de novilhas de corte em pastagem cultivada de inverno. 2003. 117f. Dissertação (Mestrado em Zootecnia)- Universidade Federal de Santa Maria.

PILLAR, V.D.P. Multivariate exploratory analysis and randomization testing with MULTIV. Coenoses, Gorizia, v.12, p.145-148, 1997.

ROSO, C.; RESTLE, J. Aveia preta, triticale e centeio em mistura com azevém. 1. Produtividade animal e retorno econômico. Revista Brasileira de Zootecnia, v.29, n.1, p.8593, 2000.

SANTOS, D.T. et al. Produção animal em pastagem cultivada com ou sem o uso de suplementos energéticos para bezerras de corte. In: REUNIÃO ANUAL DA SOCIEDADE BRASILEIRA DE ZOOTECNIA, 2002, Recife. Anais... Recife : Sociedade Brasileira de Zootecnia, 2002. CD-ROM.

SAnTOS, D.T. Avaliação bioeconômica do uso de suplementos energéticos na recria de novilhas de corte em pastagens cultivadas de verão e inverno. 2003. $104 \mathrm{f}$. 
Dissertação (Mestrado em Zootecnia)- Universidade Federal de Santa Maria.

SILVA, A.C.F. et al. Produção animal em pastagem de Aveia preta e Azevém sob diferentes níveis de biomassa de lâmina foliar verde. In: REUNIÃO ANUAL DA SOCIEDADE BRASILEIRA DE ZOOTECNIA, 40., 2003, Santa Maria. Anais... Santa Maria: Sociedade Brasileira de Zootecnia, 2003. CD ROM.
STATISTICAL ANALYSIS SYSTEM. Software SAS User's guide: Basic and statistics. Cary, NC : SAS Institute. 1996. CD ROM.

TOTHILL, J.C. et al. BOTANAL - A comprehensive sampling and computing procedure for estimating pasture yield and composition 1. Field sampling. Tropical Agronomy Technical Memorandum, Camberra, n.78, p.1-24, 1992. 